\title{
Myths and Misconceptions about Insulin Therapy among Latinos/ Hispanics with Diabetes: A Fresh Look at an Old Problem
}

\section{René Rodríguez-Gutiérrez ${ }^{1}$, Andreina Millan-Ferro ${ }^{2}$ and Enrique Caballero $A^{2 *}$}

${ }^{1}$ Endocrinology Division, Department of Internal Medicine, Hospital Universitario “Dr. José E. González" Universidad Autónoma de Nuevo León, Monterrey, Nuevo León, Mexico

${ }^{2}$ Latino Diabetes Initiative, Joslin Diabetes Center, Harvard Medical School, Boston, MA, USA

\begin{abstract}
Purpose: The purpose of this review was to identify the frequency and impact of myths and misconceptions about insulin therapy among Latino patients with diabetes. Myths are part of any culture, but can represent a strong barrier in day-to-day diabetes management.

Methods: Articles from the last 22 years (1992-2014) were searched in MEDLINE, EMBASE, Proquest and the Cochrane Central Register of Controlled Trials. Publications for this review included those that studied Latino or Hispanic patients with diabetes and were related to myths and/or misconceptions about insulin therapy.

Results: Twelve articles about misconceptions and myths related to insulin therapy in Latinos or Hispanics with diabetes met the inclusion criteria. All of them evaluated misconceptions about insulin therapy using different types of interviews and questionnaires. Negative attitudes about insulin therapy were highly prevalent among Latino patients. Many considered that insulin therapy was related to a negative life-style. Most patients feared to initiate insulin therapy and believed insulin was associated with a more advanced stage of diabetes. Blindness, amputation and dialysis were frequently considered a consequence of starting insulin therapy.

Conclusion: Misconceptions and myths about insulin therapy prevail in a large number of Latino/Hispanic patients with diabetes. They constitute important barriers when planning to start insulin therapy and may potentially jeopardize their health. Comprehensive educational programs for Latino patients with diabetes must include sessions to identify and address the presence of these misconceptions. At the same time, all health care providers caring for Latino patients with diabetes must be aware of the high prevalence of these well embedded cultural beliefs.
\end{abstract}

Keywords: Diabetes; Insulin; Myths; Misconceptions; Latino; Hispanic; Reluctant; Denial; Adherence

\section{Introduction}

Type 2 diabetes represents a mayor health problem in the U.S. and at a global level [1-3]. The Hispanic or Latino population represents the largest minority group in the U.S. with over 50 million people and it is expected that by 2050 it will compromise $24 \%$ of the U.S. population. The prevalence of diabetes in Latinos is among the highest in ethnic/ racial minorities, being close to $12 \%$ in the adult population [3-5]. Latinos are 1.8 and 1.5 times more likely to be diagnosed and to die from diabetes than non-Hispanic white adults of the same age [5-8].

Myths are defined as traditional stories or ancient beliefs to explain natural or social phenomena; they have a strong influence on life and our way of living. They are not based on scientific evidence and as a consequence, they are usually false [9]. Nonetheless, since they are passed from generation to generation and are widely accepted in many populations, especially among Latinos, they potentially represent a barrier in the day-to-day care of patients with diabetes [10-12].

Insulin is a cornerstone in diabetes treatment. Unfortunately, insulin therapy is frequently delayed leading to chronically elevated blood glucose levels that increase the risk of long-term complications in patients with diabetes. This is in part due to what has been called "clinical inertia" in health care professionals. In addition, patients' reluctance to start insulin therapy is very common and it is influenced by the presence of myths and misconception about its use, benefits and consequences. These myths frequently go unrecognized by the health care provider and can represent a barrier to implement insulin therapy [13-15]. Therefore, we decided to conduct this review with the goal of identifying how often these myths and misconceptions about insulin therapy among Latinos have been reported in the literature.

\section{Methods}

\section{Data sources and search strategy}

Articles in MEDLINE, EMBASE, Proquest and the Cochrane Central Register of Controlled Trials were searched for the last 22 years (1992-2014). "Diabetes", "Insulin", "Myths", "Misconceptions", "Latino", "Hispanic", "Reluctant", "Denial" and "Adherence" were used as key words. The search was limited to the English language and human subjects, with publication types and age groups unselected to include a wide range of results. The reference lists of relevant articles were further reviewed to identify other publications where the key words appeared in the title. To mitigate potential publication bias and maximize the search, references listed in reviews and/or primary sources were also reviewed.

*Corresponding author: Enrique Caballero A, Joslin Diabetes Center, Harvard Medical School, One Joslin Place. Boston, MA 02215, USA, Tel: (617) 2265914 Fax: (617) 226 5930; E-mail: enrique.caballero@joslin.harvard.edu

Received July 29, 2014; Accepted December 14, 2014; Published January 01, 2015

Citation: Gutiérrez RR, Ferro AM, Caballero AE (2015) Myths and Misconceptions about Insulin Therapy among Latinos/Hispanics with Diabetes: A Fresh Look at an Old Problem. J Diabetes Metab 6: 482. doi:10.4172/2155-6156.1000482

Copyright: (c) 2015 Gutiérrez RR, et al. This is an open-access article distributed under the terms of the Creative Commons Attribution License, which permits unrestricted use, distribution, and reproduction in any medium, provided the original author and source are credited. 


\section{Study selection}

The authors separately screened abstracts and titles to identify eligible articles. Selected manuscripts included the following inclusion criteria; (1) Latinos or Hispanics patients with diabetes of any age or gender (2) studies that aimed at reporting myths and misconceptions about insulin therapy and (3) manuscripts that were written in English or translated into the English language.

\section{Data abstraction}

One investigator used standardized forms to gather data on general study characteristics (study design and duration); study participants (age, sex and race); eligibility criteria; interventions (questionnaires and other study tools); outcome measures; along with their measures of variability. A second investigator confirmed the accuracy of the data gathering process. According to grading of recommendations, assessment, development and evaluation (GRADE) system all of the revised studies were analyzed [16]

\section{Results}

\section{Search yield}

Twelve articles regarding misconceptions and myths about insulin therapy among Latino or Hispanic individuals with diabetes met the established criteria [17-28]. Eleven of them were carried out in the U.S. and one in Mexico. All of them evaluated misconceptions about insulin therapy through different types of questionnaires (Table 1). According to grading of recommendations, assessment, development and evaluation (GRADE) system all of the revised studies were found to be low or verylow quality of evidence.

\section{Description of the studies}

Quatromoni et al. conducted a study in low-income Caribbean
Latinos. They found that insulin therapy was commonly not regarded as beneficial and many believed it increased the severity of the disease and that the insulin dose and diabetes complications were proportional and related [18]. In poorly controlled low-income Mexican American patients with diabetes with more that 5 years of diagnosis, Hunt et al. reported that subjects were more likely to mention negative attitudes toward insulin therapy. One third felt that receiving an insulin prescription indicated being on a very serious stage of diabetes. Costs of insulin, syringes, and self-monitoring were also a major concern. No differences were seen on attitudes between subjects on good or poor control or between insulin and non-insulin users [19].

Aloozer found that all of the patients in his study thought insulin therapy was scary and most of them believed that being on insulin could be associated with blindness, renal dialysis and amputations [20] Similarly, Poss et al. found that all of the participants not on insulin therapy were concerned about having to use it in the future, had the belief that using insulin indicated a more severe form of diabetes and were worried that blindness and dependence on insulin were potential adverse events [21].

Polonsky et al. developed and distributed a "psychological insulin resistance" PIR self-reported survey to examine willingness of patients to take insulin if it was prescribed and to identify perceived attitudinal barriers on insulin therapy. The results showed that many of the subjects were unwilling or had only slight to moderate willingness to initiate on insulin. Ethnic minorities (35.1\%) were more unwilling to insulin than non-Hispanic patients $(\mathrm{p}=\leq 0.01)$. The most negative attitude (45\%) was the belief that once started on insulin there was never a possibility of quitting. Fear about hypoglycemia was $40.6 \%$ and the impression that insulin was related to a more serious disease stage was also common. When comparing the attitudes of subjects

\begin{tabular}{|c|c|c|c|}
\hline Authors & Type of Population & Type of Study & Main Findings \\
\hline $\begin{array}{l}\text { 1. Quatromoni et al. } \\
\text { [18] }\end{array}$ & 34 type 2 low-income Caribbean Latinos & Group Interviews & $\begin{array}{l}\text { - Insulin was not regarded as beneficial. } \\
\text { - Many believed that insulin dose and complications were related. }\end{array}$ \\
\hline $\begin{array}{l}\text { 2. Hunt et al. } \\
{[19]}\end{array}$ & $\begin{array}{l}44 \text { type } 2 \text { diabetes low-income Mexican } \\
\text { Americans }\end{array}$ & $\begin{array}{l}\text { Open-ended in-depth } \\
\text { interviewing techniques. }\end{array}$ & $\begin{array}{l}\text { - Negative attitude more likely } \\
\text { than positive }(75-25 \%) \text {. } \\
\text { - Believed caused serious } \\
\text { health problems }(43 \%) \text {. } \\
\text { - Blindness myth }(25 \%) \text {. }\end{array}$ \\
\hline $\begin{array}{l}\text { 3. Aloozer et al. } \\
\text { [20] }\end{array}$ & $\begin{array}{l}20 \text { type } 2 \text { diabetes Mexican American } \\
\text { Women }\end{array}$ & Open-ended interviews & $\begin{array}{l}\text { - Insulin therapy is scary }(100 \%) \text {. } \\
\text { - Insulin is related to blindness, renal dialysis and amputations }(90 \%) \text {. }\end{array}$ \\
\hline $\begin{array}{l}\text { 4. Poss et al. } \\
\text { [21] }\end{array}$ & 22 type 2 diabetes Mexican Americans & Open-ended questionnaire & $\begin{array}{l}\text { - All non-insulin users were concerned about future use. } \\
\text { - Using insulin was related to have a more severe disease. }\end{array}$ \\
\hline $\begin{array}{l}\text { 5. Polonski et al. } \\
\text { [22] }\end{array}$ & 1,267 type 2 diabetes & Questionnaire & $\begin{array}{l}\text { - Were unwilling to start insulin }(28.2 \%) \text {. } \\
\text { - Thought insulin restricts life }(44.8 \%) \text {. } \\
\text { - Insulin is associated to a advanced diabetes stage (38.1\%). }\end{array}$ \\
\hline $\begin{array}{l}\text { 6. Peyrot et al. } \\
\text { [17] }\end{array}$ & $\begin{array}{l}2,061 \text { type } 1 \text { and tyo } 2 \text { diabetes, } \\
1109 \text { nurses and } 2681 \text { physicians }\end{array}$ & Surveys & $\begin{array}{l}\text { - Patients rated insulin efficacy as low } \\
\text { - } 34 \% \text { of physicians and } 54 \% \text { of nurses delayed insulin therapy }\end{array}$ \\
\hline $\begin{array}{l}\text { 7. Lingvay et al. } \\
\text { [23] }\end{array}$ & 58 type 2 diabetes ( $37.9 \%$ Latino) & Questionnaire & $\begin{array}{l}3 \text { months after started on insulin therapy: } \\
\text { - Were satisfied with insulin }(97 \%) \text {. } \\
\text { - Were willing to continue insulin }(88 \%)\end{array}$ \\
\hline $\begin{array}{l}\text { 8. Lerman et al. } \\
\text { [24] }\end{array}$ & 29 type 2 diabetes low-income Mexicans & Questionnaires & $\begin{array}{l}\text {-Believed insulin was related to advance disease }(89 \%) \\
\text { - Blindness myth }(37 \%) \\
\text { - Insulin was expensive }(31 \%)\end{array}$ \\
\hline $\begin{array}{l}\text { 9. Mann et al. } \\
\text { [25] }\end{array}$ & $\begin{array}{l}151 \text { type } 2 \text { diabetes low-income minorities } \\
\text { (58\% Latinos) }\end{array}$ & Cross Sectional Survey & $\begin{array}{l}\text { - Found not important to take insulin when glucose was normal }(23 \%) \text {. } \\
\text { - Worried about potential addiction }(13 \%) \text {. }\end{array}$ \\
\hline $\begin{array}{l}\text { 10. Karter et al. } \\
\text { [26] }\end{array}$ & 169 type 2 diabetes (15\% Latinos) & Interviews and surveys & $\begin{array}{l}\text { - Blindness myth (35\%). } \\
\text { - Concerned about insulin cost (25\%). }\end{array}$ \\
\hline $\begin{array}{l}\text { 11. Hu et al. } \\
\text { [27] }\end{array}$ & 43 Latinos with type 2 diabetes & Surveys & $\begin{array}{l}\text { - Highly negative perceptions about insulin } \\
\text { - Fear insulin could produce organ damage or death. }\end{array}$ \\
\hline $\begin{array}{l}\text { 12. Peyrot et al. } \\
\text { [28] }\end{array}$ & $\begin{array}{l}110 \text { type } 1 \text { and } 1420 \text { type } 2 \text { diabetes } \\
(10 \% \text { Spain, } 22.9 \% \text { US) }\end{array}$ & Questionnaire & $\begin{array}{l}\text { Omission/adherence was } 34.6 \% \text { and was higher among those who } \\
\text { believed insulin was less important and perceived insulin as impacting } \\
\text { life-style. }\end{array}$ \\
\hline
\end{tabular}

Table 1: Description of studies addressing myths and misconceptions about insulin therapy among Latino patients with diabetes. 
that reported being unwilling against those who were willing, the most common negative attitude was that they had "failed" proper diabetes self-management; additionally 16 vs. $8 \%$ expected insulin to be harmful. (insulin can cause problems such as blindness) [22].

The diabetes attitudes, wishes and needs (DAWN) study had the primary objective to correlate the patient and provider attitudes toward insulin therapy. Results showed that patients rated insulin efficacy as low and blamed themselves if they had to start on insulin therapy. Patients that had worse control were more likely to see insulin as potentially beneficial. Interestingly, it was found that many physicians and nurses delayed insulin therapy until absolutely necessary. This was more prevalent among U.S. providers than in physicians of other parts of the world [17]. On the other hand, Lingvay et al. described that almost every patient that used insulin for the first time during this study was satisfied with insulin treatment and was willing to continue with the therapy [23].

With the objective of evaluating the psychosocial barriers to insulin therapy and possible causes of non-adherence to insulin, Lerman et al. found that most of the patients believed they had to use insulin because their disease was worse. Seventy-two percent assumed that they wouldn't need insulin and could avoid it if they adhered better to their previous treatment. Many considered insulin caused blindness, was too expensive and would complicate their lifestyle [24]. More recently, Mann et al. found that regardless of diabetes duration and care settings, patients frequently hold beliefs about insulin therapy. When comparing insulin users vs. non users, they found that; $43 \%$ vs. 55\% thought that the consequences of diabetes were low, $24 \%$ vs. 35\% believed doctors were able to cure diabetes, $28 \% v s$. $17 \%$ did not think it was important to take medications when glucose is normal, $13 \%$ vs. $19 \%$ are worried about addictions to diabetes medications and $24 \%$ vs. $10 \%$ believe diabetes medications are hard to take. In general they found patients to have unrealistic expectations about the treatment of diabetes [25]. Later on, Karter et al. frequently found that patients thought insulin caused blindness, renal failure, amputations, heart attacks, strokes, or early death. Some also believed insulin may negatively impact their social life and were concerned about insulin cost [26].

$\mathrm{Hu}$ et al. found that a high number of patients expressed negative perceptions about insulin therapy and feared that using it could produce organ damage or even death [27]. Finally, the global attitudes of patients and physicians in insulin therapy (GAPP) study, examined factors associated with insulin injection omission/non-adherence on a global basis. It found that omission/non-adherence was frequent and significantly higher among those who believed insulin adherence was less important, perceived insulin therapy as impacting lifestyle, saw insulin injections as a difficult task and were less satisfied with the flexibility of the insulin regimen. When they analyzed the subset of U.S. insulin treated patients, it was found that $42 \%$ of the respondents had omitted insulin in the last month and $27 \%$ had omitted insulin more than one day in the last month [28].

\section{Discussion}

The main finding of this review is that misconceptions and myths among Latinos with diabetes are highly prevalent and may be commonly encountered in day-to-day clinical practice. They can easily represent an important barrier for physicians when trying to start and sustain insulin therapy. This obstacle may lead to uncontrolled diabetes that can increase the likelihood of chronic microvascular and macrovascular complications. Negative attitudes towards insulin were particularly predominant among insulin naïve subjects, having some or complete unwillingness to start insulin therapy. Misconceptions that prevailed were the idea that being on insulin indicated an advanced stage of diabetes, and that this therapy would restrict their life and was hard to follow. They often reported fear and anxiety about the injections and adverse events such as hypoglycemia. The beliefs that insulin was associated and could potentially produce blindness, dialysis, amputations and that insulin therapy was expensive were very common. Although present in a smaller number of individuals, some were convinced that insulin was not beneficial, could increase the severity of diabetes and create potential addiction. The presence of myths and misconceptions were not always more prevalent among those patients with poor control when compared with those with good control, but in general, patients in a more advanced disease were more likely to see insulin as potentially beneficial. This could be explained by patients already being used to take insulin for some time. Table 2 shows the main concerns about insulin therapy in the Latino population.

The experience in the Latino Diabetes Initiative at Joslin Diabetes Center confirms some of these observations. We studied 120 Latino patients with long lasting type 2 diabetes of which $81 \%$ had uncontrolled diabetes (A1C $\geq 7.0 \%$ ) and $41 \%$ were on insulin therapy. We found that $39 \%$ of all studied patients believed that insulin caused blindness (blindness myth). Illiteracy and less years of education were significantly related with this misconception. Among the patients who believed the blindness myth compared to those who didn't, we found that they had a poorer perception of their health, were more likely to have insulin omission, had greater emotional distress, lower adherence, modified their treatment without recommendation, were less likely to measure their blood glucose levels and were more prone to miss their appointments ( $\mathrm{P}=\leq 0.05$ for all comparisons). Most of the patients had health insurance coverage and higher educational level $(10.3 \pm 5.8$ years of education) than the majority of Latino patients in the U.S. and therefore may underestimate the real prevalence of this belief [29].

It is important to highlight that these myths and misconceptions are not exclusive of the Latino population since other studies around the world have also addressed this same issue in other groups. For instance, a study in Malaysia reported that $41 \%$ of the patients were unwilling to start insulin therapy, $59.2 \%$ saw insulin as a personal failure, $55.9 \%$ as embarrassing, $50.7 \%$ as painful and $40 \%$ though it restricted their life in 404 diabetic patients [30]. In a study in Saudi Arabia, Sabra et al. found that, $32 \%$ of 1030 patients with diabetes believed that prolonged use of insulin therapy could lead to serious side effects and $38 \%$ than herbs were a better treatment that insulin or oral anti-diabetic drugs [31]. Nakar et al. reported a study in 92 patients with diabetes in Israel that met the criteria to start insulin therapy, but had not yet initiated it. They found that $46 \%$ thought they had not a very serious illness, $39 \%$ had fear of addiction and $11 \%$ believed that insulin wouldn't

\section{Insulin is...}

- Associated with blindness and other diabetes-related complications

- Linked with a more severe/advanced disease

Related with a negative life-style

- A punishment

- Scary

Difficult to administrate

- Expensive

Not beneficial

Addictive

- Harmful

- Related to a more difficult and time consuming self-care management

Table 2: Main concerns about insulin therapy among Latino with diabetes. 
help [32]. A study in India that included 52 patients with diabetes that had failed to control their disease with oral anti-diabetic agents, $69 \%$ declined to start insulin, $88 \%$ where scared of insulin injection and $50 \%$ believed that insulin damaged other organs [33]. In general myths and misconceptions about insulin therapy tend to prevail around most parts of the world, particularly in areas where illiteracy, low-income and a compromised social structure predominates.

Insulin is the most potent anti-diabetic medication to reduce glucose levels and it has proven to lower microvascular and long-term macrovascular events in both type 1 and type 2 diabetes. However, it remains usually a difficult threshold for many patients to cross $[13,34$ 38]. In addition to provider obstacles such as lack of time, lack of resources, and clinical inertia, cultural misconceptions or myths among patients with diabetes are common barriers to insulin therapy initiation [34-40]. Since by the time of diagnosis of type 2 diabetes, patients have lost close to over $80 \%$ of their beta-cell pancreatic function, it is not surprising that insulin therapy will eventually be needed in most patients to achieve glycemic goals $[1,41,42]$.

Interestingly, there are several studies that report that once the barrier of insulin use is crossed patients with diabetes usually tend to have a better attitude and approach towards insulin therapy $[28,32,43$ 45]. Therefore, the identification of these misconceptions early in the course of the disease is crucial. Patient-centered assessment techniques have been found useful in exploring the cause of some of these misconceptions $[46,47]$. These myths among Latinos are multifactorial in origin and derive from of complex behavioral, social, cultural, emotional, and medical components of the human experience in health and illness [48]. The Latino Diabetes Initiative at Joslin Diabetes Center has included patient education activities and materials to routinely identify and overcome frequent myths and misconceptions about diabetes in our patients $[15,49,50]$.

According to grading of recommendations, assessment, development and evaluation (GRADE) system all of the revised studies were found to be low or very-low quality of evidence [16]. This could be seen as a limitation of the study. Nevertheless, this was expected as in this kind of studies avoiding bias is difficult to achieve and because of its nature it will be unlikely that at some point this type of research question could be analyzed by a randomized controlled trial.

\section{Conclusion}

In conclusion, misconceptions and myths about insulin therapy prevail in a large number of Latino/Hispanic patients with diabetes. They constitute important barriers when planning to start insulin therapy and may potentially jeopardize their health. Comprehensive educational programs for Latino patients with diabetes must include sessions to identify and address the presence of these myths and misconceptions. At the same time, all health care providers providing caring for Latino patients with diabetes must be aware of the high prevalence of these very well embedded cultural beliefs.

\section{References}

1. American Diabetes Association (2014) Standards of medical care in diabetes--2014. Diabetes Care 37 Suppl 1: S14-80.

2. World Health Organization (WHO) (2011) Fact Sheet 312 August 2011.

3. National Center for Chronic Disease Prevention and Health Promotion (2011) National Diabetes Fact Sheet 2011

4. Ramirez RR, De la Cruz PG (2002) The Hispanic Population in the United States: March 2002. Current Population Reports, P20-545. Census Bureau, Washington, DC, U.S.

5. Caballero AE (2006) Building cultural bridges: understanding ethnicity to improve acceptance of insulin therapy in patients with type 2 diabetes. Ethn Dis 16: $559-568$

6. Centers for Disease Control and Prevention (CDC) (2013) Estimated percentages and characteristics of men who have sex with men and use injection drugs--United States, 1999-2011. MMWR Morb Mortal Wkly Rep 62 : 757-762.

7. Millan-Ferro A, Caballero AE (2007) Cultural approaches to diabetes selfmanagement programs for the Latino community. Curr Diab Rep 7: 391-397.

8. Boyle JP, Honeycutt AA, Narayan KM, Hoerger TJ, Geiss LS, et al. (2001) Projection of diabetes burden through 2050: impact of changing demography and disease prevalence in the U.S. Diabetes Care 24: 1936-1940.

9. Paauw DS (1999) Did we learn evidence-based medicine in medical school? Some common medical mythology. J Am Board Fam Pract 12: 143-149.

10. Lai WA, Lew-Ting CY, Chie WC (2005) How diabetic patients think about and manage their illness in Taiwan. Diabet Med 22: 286-292.

11. Hatcher E, Whittemore R (2007) Hispanic adults' beliefs about type 2 diabetes: clinical implications. J Am Acad Nurse Pract 19: 536-545.

12. Caballero AE (2007) Cultural competence in diabetes mellitus care: An urgent need. Insulin 2: 80-91.

13. Inzucchi SE, Bergenstal RM, Buse JB, Diamant M, Ferrannini E, et al (2012) Management of hyperglycemia in type 2 diabetes: a patient-centered approach: position statement of the American Diabetes Association (ADA) and the European Association for the Study of Diabetes (EASD). Diabetes Care 35: $1364-1379$.

14. Caballero AE (2007) Improving diabetes care and education of Latinos: a challenging but important mission. Curr Diab Rep 7: 321-323.

15. Caballero AE1 (2011) Understanding the Hispanic/Latino patient. Am J Med 124: S10-15.

16. Swiglo BA, Murad MH, Schünemann HJ, Kunz R, Vigersky RA, et al. (2008) A case for clarity, consistency, and helpfulness: state-of-the-art clinical practice guidelines in endocrinology using the grading of recommendations, assessment, development, and evaluation system. J Clin Endocrinol Metab 93 666-673.

17. Peyrot M, Rubin RR, Lauritzen T, Skovlund SE, Snoek FJ, et al. (2005) Resistance to insulin therapy among patients and providers: results of the cross-national Diabetes Attitudes, Wishes, and Needs (DAWN) study. Diabetes Care 28: 2673-2679.

18. Quatromoni PA, Milbauer M, Posner BM, Carballeira NP, Brunt M, et al. (1994) Use of focus groups to explore nutrition practices and health beliefs of urban Caribbean Latinos with diabetes. Diabetes Care 17: 869-873.

19. Hunt LM, Valenzuela MA, Pugh JA (1997) NIDDM patients' fears and hopes about insulin therapy. The basis of patient reluctance. Diabetes Care 20: 292298.

20. Alcozer $F$ (2000) Secondary analysis of perceptions and meanings of type 2 diabetes among Mexican American women. Diabetes Educ 26: 785-795.

21. Poss JE, Jezewski MA, Stuart AG (2003) Home remedies for type 2 diabetes used by Mexican Americans in El Paso, Texas. Clin Nurs Res 12: 304-323.

22. Polonsky WH, Fisher L, Guzman S, Villa-Caballero L, Edelman SV (2005) Psychological insulin resistance in patients with type 2 diabetes: the scope of the problem. Diabetes Care 28: 2543-2545.

23. Lingvay I, Kaloyanova PF, Adams-Huet B, Salinas K, Raskin P (2007) Insulin as initial therapy in type 2 diabetes: effective, safe, and well accepted. J Investig Med 55: 62-68.

24. Lerman I, Díaz JP, Ibarguengoitia ME, Pérez FJ, Villa AR, et al. (2009) Nonadherence to insulin therapy in low-income, type 2 diabetic patients. Endocr Pract 15: 41-46.

25. Mann DM, Ponieman D, Leventhal H, Halm EA (2009) Misconceptions about diabetes and its management among low-income minorities with diabetes. Diabetes Care 32: 591-593.

26. Karter AJ, Subramanian U, Saha C, Crosson JC, Parker MM, et al. (2010) Barriers to insulin initiation: the translating research into action for diabetes insulin starts project. Diabetes Care 33: 733-735.

27. Hu J, Amirehsani KA, Wallace DC, Letvak S (2012) The meaning of insulin to 
Citation: Gutiérrez RR, Ferro AM, Caballero AE (2015) Myths and Misconceptions about Insulin Therapy among Latinos/Hispanics with Diabetes: A Fresh Look at an Old Problem. J Diabetes Metab 6: 482. doi:10.4172/2155-6156.1000482

Page 5 of 5

Hispanic immigrants with type 2 diabetes and their families. Diabetes Educ 38 : 263-270.

28. Peyrot M, Barnett AH, Meneghini LF, Schumm-Draeger PM (2012) Factors associated with injection omission/non-adherence in the Global Attitudes of Patients and Physicians in Insulin Therapy study. Diabetes Obes Metab 14: 1081-1087.

29. Herrero M, Milan A, Caballero AE (2006) The presence of the blindness myth in Latino patients with type 2 diabetes. Presented in the International Diabetes Federation Meeting.

30. Azmiah NZ, Zulkarnaid AK, Tahir A (2011) Psychological insulin resistance (PIR) among type 2 diabetes patients at public health clinics in federal territory of Malaysia. International Medical Journal of Malaysia 10: 7-12.

31. Sabra AA, Taha AZ, Al-Zubier AG, Al-Kurashi NY (2010) Misconceptions about diabetes mellitus among adult male attendees of primary health care centers in Eastern Saudi Arabia. SA Fam Pract 52: 344-349.

32. Nakar S, Yitzhaki G, Rosenberg R, Vinker S (2007) Transition to insulin in Type 2 diabetes: family physicians' misconception of patients' fears contributes to existing barriers. J Diabetes Complications 21: 220-226.

33. Sircar AR, Sircar S, Sircar J, Misra S (2010) Patients' concepts and attitudes about diabetes. J Diabetes Complications 24: 398-403.

34. (1998) Intensive blood-glucose control with sulphonylureas or insulin compared with conventional treatment and risk of complications in patients with type 2 diabetes (UKPDS 33). UK Prospective Diabetes Study (UKPDS) Group. Lancet 352: 837-853.

35. (1993) The effect of intensive treatment of diabetes on the development and progression of long-term complications in insulin-dependent diabetes mellitus. The Diabetes Control and Complications Trial Research Group. N Engl J Med 329: 977-986.

36. Nathan DM, Cleary PA, Backlund JY, Genuth SM, Lachin JM, et al. (2005) Intensive diabetes treatment and cardiovascular disease in patients with type 1 diabetes. Diabetes Control and Complications Trial/Epidemiology of Diabetes Interventions and Complications (DCCT/EDIC) Study Research Group N Engl J Med 353: 2643.

37. Holman RR, Paul SK, Bethel MA, Matthews DR, Neil HA (2008) 10-year followup of intensive glucose control in type 2 diabetes. N Engl J Med 359: 1577 1589.
38. Shah BR, Hux JE, Laupacis A, Zinman B, van Walraven C (2005) Clinical inertia in response to inadequate glycemic control: do specialists differ from primary care physicians? Diabetes Care 28: 600-606.

39. Siminerio $L$ (2006) Challenges and strategies for moving patients to injectable medications. Diabetes Educ 32 Suppl 2: 82S-90S.

40. Peyrot M, Rubin RR, Lauritzen T, Skovlund SE, Snoek FJ, et al. (2005) Resistance to insulin therapy among patients and providers: results of the cross-national Diabetes Attitudes, Wishes, and Needs (DAWN) study. Diabetes Care 28: 2673-2679.

41. Defronzo RA (2009) Banting Lecture. From the triumvirate to the ominous octet: a new paradigm for the treatment of type 2 diabetes mellitus. Diabetes 58: 773-795.

42. IDF Clinical Guidelines Task Force (2006) Global Guideline for Type 2 Diabetes: recommendations for standard, comprehensive, and minimal care. Diabet Med 23: 579-593.

43. Dailey GE 3rd (2005) Early insulin: an important therapeutic strategy. Diabetes Care 28: 220-221.

44. Meneghini LF (2009) Early insulin treatment in type 2 diabetes: What are the pros? Diabetes Care 32: 266-269.

45. (1999) Quality of life in type 2 diabetic patients is affected by complications but not by intensive policies to improve blood glucose or blood pressure control (UKPDS 37). U.K. Prospective Diabetes Study Group. Diabetes Care 22: 11251136.

46. Larkin ME, Capasso VA, Chen CL, Mahoney EK, Hazard B, et al. (2008) Measuring psychological insulin resistance: barriers to insulin use. Diabetes Educ 34: 511-517.

47. Peragallo-Dittko V (2007) Removing barriers to insulin therapy. Diabetes Educ 33 Suppl 3: 60S-65S

48. Caballero AE (2007) Type 2 diabetes in the Hispanic or Latino population challenges and opportunities. Curr Opin Endocrinol Diabetes Obes 14: 151 157.

49. Caballero AE, Ward K, Hill J, Belen C (2004) The Latino Diabetes Initiative: comprehensive clinical care, education and research program to improve lives of Latinos with diabetes and at risk for the disease. Diabetes 53: A552-A553.

50. Latino Diabetes Initiative at Joslin Diabetes Center. 